\title{
Anatomical study of the teres major muscle: description of an additional distal muscle slip
}

\author{
Lukas Ernstbrunner ${ }^{1 *}$ (D), Malik Jessen ${ }^{1}$, Marco Rohner ${ }^{1}$, Manuel Dreu², Samy Bouaicha ${ }^{1}$, Karl Wieser ${ }^{1}$ and \\ Paul Borbas ${ }^{1}$
}

\begin{abstract}
Background: Understanding muscle and tendon anatomy is of tremendous importance to achieve optimal surgical execution and results in tendon transfers around the shoulder. The aim of this study was to introduce and describe an additional distal muscle slip of the teres major (TM).

Methods: Sixteen fresh-frozen cadaver shoulders were dissected with the deltopectoral approach. The ventral latissimus dorsi (LD) tendon was harvested, and the shoulders were analyzed for the presence/absence of a distal teres major slip (dTMs) and its dimensions and relationship with the TM and LD tendons.

Results: The dTMs was identified in 12 shoulders (75\%). It was always distal to the TM tendon and visible during the deltopectoral approach. There was a clear separation between the TM proximally and dTMs tendon distally. At the humeral insertion, both tendons had a common epimyseal sheet around the teres major and inserted continuously at the humerus. The mean width of the dTMs tendon at the insertion was $13 \pm 4 \mathrm{~mm}$ (range, 7-22 mm). The total lengths of the dTMs tendon and LD tendon were $40 \pm 7 \mathrm{~mm}$ (range, $25-57 \mathrm{~mm}$ ) and $69 \pm 7 \mathrm{~mm}$ (range, $57-79 \mathrm{~mm}$ ), respectively $(p<0.001)$. The dTMs muscle showed direct adhesions in ten shoulders (83\%) with the LD muscle.

Conclusions: This is the first macroscopic description of an additional distal slip of the teres major muscle. The dTMs has a separate (distal) but continuous (mediolateral) insertion at the humerus within a common epimyseal sheet around the TM. The dTMs tendon is visible during the deltopectoral approach and can therefore provide a lead structure, particularly in ventral LD transfers with the deltopectoral approach.
\end{abstract}

Keywords: Teres major muscle, Distal teres major slip, Latissimus dorsi muscle, Tendon transfer, Deltopectoral approach

\section{Background}

In 1934, L 'Episcopo first described the teres major (TM) and then the latissimus dorsi (LD) transfer in the treatment of obstetric brachial plexus palsy in six children [1]. More than 50 years later, Gerber et al. noted that adults with irreparable posterosuperior rotator cuff tears

\footnotetext{
* Correspondence: lukas.ernstbrunner@balgrist.ch

Investigation performed at the Balgrist University Hospital

'Department of Orthopedics, Balgrist University Hospital, University of Zurich, Forchstrasse 340, 8008 Zurich, Switzerland

Full list of author information is available at the end of the article
}

have similar abduction and external rotation deficits as children diagnosed with plexus palsy [2]. Therefore, they treated these patients with an isolated LD transfer using the two-incision technique and found good functional results [3, 4]. Boileau et al. modified the L'Episcopo tendon transfer technique by transferring LD combined with TM using the deltopectoral approach [5]. In addition, an isolated TM transfer has been described [6], and more recently, the ventral LD transfer for reconstruction of irreparable anterosuperior rotator cuff tears has been proposed [7-9].

(c) The Author(s). 2021 Open Access This article is licensed under a Creative Commons Attribution 4.0 International License, which permits use, sharing, adaptation, distribution and reproduction in any medium or format, as long as you give appropriate credit to the original author(s) and the source, provide a link to the Creative Commons licence, and indicate if changes were made. The images or other third party material in this article are included in the article's Creative Commons licence, unless indicated otherwise in a credit line to the material. If material is not included in the article's Creative Commons licence and your intended use is not permitted by statutory regulation or exceeds the permitted use, you will need to obtain permission directly from the copyright holder. To view a copy of this licence, visit http://creativecommons.org/licenses/by/4.0/ The Creative Commons Public Domain Dedication waiver (http://creativecommons.org/publicdomain/zero/1.0/) applies to the data made available in this article, unless otherwise stated in a credit line to the data. 
For all tendon transfers around the shoulder, an anatomical understanding of the tendon insertions and relationship between each other is of tremendous importance. In LD tendon transfers, it is required that the LD is released from its insertion and surrounding soft tissue and finally mobilized to minimize tension and potential damage to the adjacent nerves. Any abnormality or interconnection between the transferred tendon and the surrounding tissue may impair tendon mobility. Several authors have therefore studied the relationship between $\mathrm{LD}$ and TM, particularly the insertion variants of the tendons [7, 10-18], and described different anatomic variants of TM [19-24]. As such, an additional strand of muscle fibers proximal to TM was observed and named as the TM accessorius [16].

However, to our knowledge, no study has described a distal slip of the TM, which was incidentally observed by the reporting authors during LD transfer surgery. Therefore, the purpose of this study was to investigate the anatomy of the distal teres major slip (dTMs) and to describe its relationship with the TM and LD in freshfrozen cadaver shoulders.

\section{Methods}

The primary goal of this cadaveric study was to analyze the presence and anatomy of the dTMs in relation to the TM and LD. All donors had given their informed consent to use their bodies for scientific purposes and the specimens were purchased through Science Care (Florida, USA). After ethical approval of this study, no specific consent was required for use of these specimens in this study.

\section{Dissection}

As determined on computed tomography, 16 freshfrozen cadaver shoulder specimens (seven right and nine left shoulders) of 16 hemitorsi had intact glenohumeral joints. Donors included nine men and seven women, all of which were white Americans, with a mean age of $82 \pm 7$ years at death. All shoulders were thawed for $24 \mathrm{~h}$ at room temperature prior to dissection and dissected using the deltopectoral approach by two fellowshiptrained shoulder surgeons (LE, PB). After removing the skin, superficial tissue, and pectoralis major muscle, the tendon of the LD could be identified. The LD and TM tendons were carefully separated from the surrounding tissue. After the LD tendon was separated from the underlying TM at its site of humeral insertion, the LD tendon was harvested to obtain a full view of the TM insertion. The TM muscle was then macroscopically checked for the presence of dTMs. When the dTMs was present, the muscle and tendon were dissected in entirety. Finally, the TM with the attached dTMs were harvested for ex situ photo documentation.

\section{Cadaveric measurements}

Measurements were performed with the arm in the neutral $\left(0^{\circ}\right.$ abduction $)$ position. Using a tape ruler, the dimensions of the dTMs and LD tendons and muscles were measured. Before the LD tendon was harvested, the LD tendon length and width at the bony insertion were measured in all specimens. Second, the presence of the dTMs was examined, and when present, tendon location relative to the TM and LD, tendon width at insertion and width in continuity, and full tendon length were measured. If the dTMs was adherent to the LD, the distance from the bony insertion to the adherence was documented.

\section{Statistical analysis}

The Shapiro-Wilk test was applied to test the data for normal distribution. Continuous variables are expressed as mean \pm standard deviation. The paired t-test was used to compare the widths of the LD and dTMs tendons as well as the dTMs tendon width at the bony insertion with that in continuity. The alpha level was set to 0.05 , and all $p$-values were two-tailed.

\section{Results}

In 12 out of 16 (75\%) shoulders, the dTMs was present. Its tendon was in 12 out of 12 shoulders distal to the TM tendon and visible during the deltopectoral approach with the LD tendon attached. In the remaining four shoulders (25\%), no dTMs was observed, and TM and LD had a common (conjoint) tendon insertion. Once the LD was resected, a clear separation between the TM proximally and the dTMs distally, was observed. The dTMs tendon showed a distinct insertion, which was separate distally from that of the TM insertion and within a common epimyseal sheet around the TM, which formed a continuous humeral insertion (Fig. 1).

Compared to the LD tendon, the width of the dTMs tendon at the bony insertion was half the size (LD, $27 \pm$ $4 \mathrm{~mm}$ vs. dTMs, $13 \pm 4 \mathrm{~mm} ; p<0.001)$. The mean dTMs tendon width decreased by more than a third from the bony insertion to the musculotendinous unit $(13 \pm 4 \mathrm{~mm}$ vs. $8 \pm 3 \mathrm{~mm} ; p<0.001)$. The total lengths of the dTMs and LD tendons were $40 \pm 7 \mathrm{~mm}$ and $69 \pm 7 \mathrm{~mm}$, respectively $(p<0.001)$. In 10 of $12(83 \%)$ shoulders, the dTMs muscle showed direct adhesions to the LD muscle. These band-like connections (connectiones intertendineae) were located at a mean distance of $50 \pm$ $8 \mathrm{~mm}$ proximal to the bony insertion of dTMs (Table 1 ).

After resection of the TM and dTMs muscles, the muscle belly of the dTMs was ventral to that of the TM muscle and the tendons of both muscles were separate (Fig. 2). 


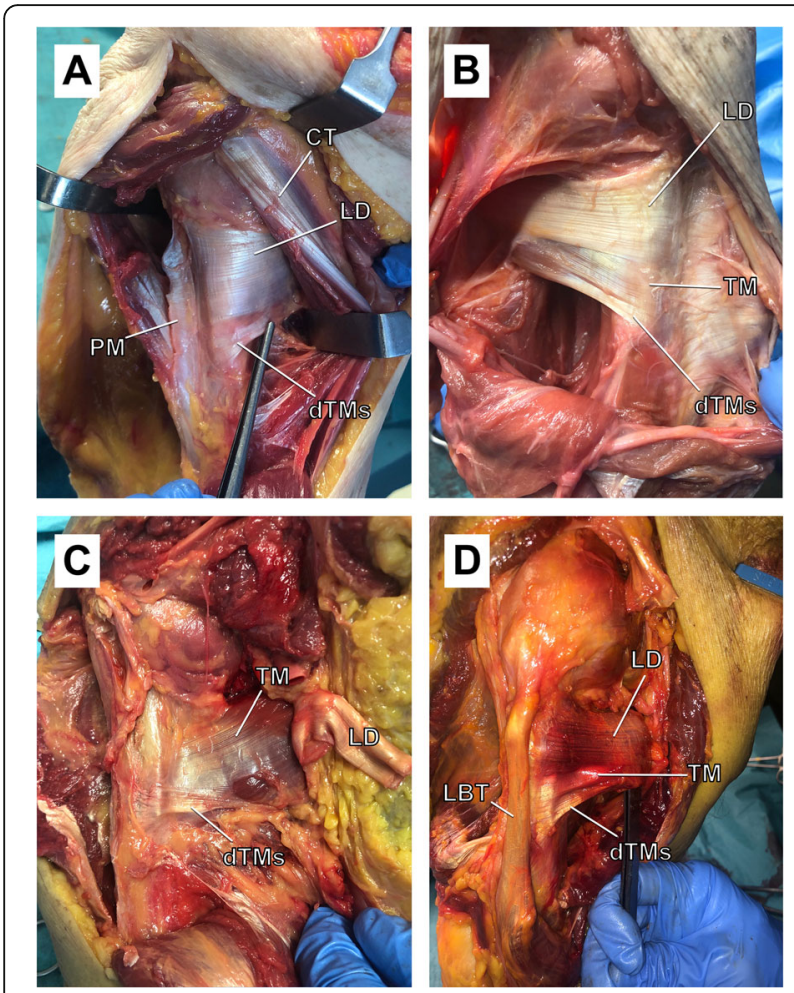

Fig. 1 a to $\mathbf{d}$ The anterior view of the humerus after the deltopectoral approach and resection of the pectoralis major tendon. The insertion site of the tendons on the humerus in four different specimens (a, c, and $\mathbf{d}$ : left side; $\mathbf{b}$ : right side) with the presence of the distal teres major slip. Note the separate (distal) but continuous (mediolateral) insertion of the distal teres major slip within a common epimyseal sheet around the TM. LBT, long biceps tendon; LD, latissimus dorsi; PM, pectoralis major; TM, teres major; dTMs, distal teres major slip

\section{Discussion}

In the present anatomical study, we introduced and described a muscle-tendon slip distal to the TM, which seems to be an additional head of the TM muscle. The dTMs has a separate (distal) but continuous (mediolateral) insertion at the humerus within a common epimyseal sheet around the TM. Other than the previously described TM accessorius [16], which lies proximally, the described additional head is located distal to the TM. This distal teres major slip was identified in $75 \%$ of our shoulder specimens, and its presence was defined by a distinct and separate bony insertion distal to the tendon insertion of the TM.

The LD tendon attaches more laterally and proximally compared to the TM tendon with the most inferior portion of the insertion area of the TM usually located inferior to that of the LD tendon $[16,25]$, leaving parts of the TM bony insertion visible during a deltopectoral approach. Yet, separation of the LD and TM tendon insertions during this approach can be challenging. If present, intraoperative exposure of the dTMs tendon may provide an additional distal lead structure for separating the tendon insertions between the LD and TM when using the deltopectoral approach for tendon transfer surgery. In particular, for isolated LD transfers [5], where the TM is left at its anatomical position, an exact differentiation of the insertion sites between LD and TM is fundamentally important to perform a correct tendon transfer.

Beger et al. classified the interconnections between LD and TM into five different types [17]: type 1 referred to no muscular or tendinous connections, type $2 / 3$ to muscular connections, and type $4 / 5$ to tendinous connections. Wang et al. described additional muscle fibers, which cover the TM tendon posteriorly and attach directly to the periosteum of the humerus [10]. Moreover, Dancker et al. described an additional strand of muscle fibers proximal to TM [16]. The authors assumed an additional head of the TM with considerable thickness and separate bony insertion by a short tendon and named it TM accessorius. Also, several studies reported on additional/anomalic slips of the TM which pass between TM and the long head of the triceps [19-21], or between TM and the fascia of the shoulder capsule and the brachialis fascia $[19,22]$, or from the biceps brachii to the TM [23], or from the tendon of coracobrachialis to the TM [19], or even from the infraglenoid tubercle to the TM [24]. However, to the best of our knowledge, this is the first study describing an additional distal muscle slip of the TM. In contrast to the TM accessorious, which inserts proximally and medially to the main insertion of the TM [16], the dTMs inserts as a separate and distal tendon with a continuous insertion at the humerus within a common epimyseal sheet around the TM.

Table 1 Dimensions of the latissimus dorsi and distal teres major slip ${ }^{a}$

\begin{tabular}{lllll}
\hline & $\begin{array}{l}\text { Tendon width at } \\
\text { insertion }(\mathbf{m m})\end{array}$ & $\begin{array}{l}\text { Tendon width in } \\
\text { continuity }(\mathbf{m m})\end{array}$ & Total tendon length $(\mathbf{m m})$ & $\begin{array}{l}\text { Distance to adhesions } \\
\text { with LD (mm) }\end{array}$ \\
\hline dTMs $(n=12)$ & $13 \pm 4(7-22)$ & $8 \pm 3(4-13)$ & $40 \pm 7(25-57)$ & $50 \pm 8(39-64)^{b}$ \\
LD $(n=16)$ & $27 \pm 4(22-34)$ & & $69 \pm 7(48-83)$ & \\
$p$-value & 0.001 & & 0.001 & \\
\hline
\end{tabular}

LD Latissimus dorsi, dTMs Distal teres major slip

a Data are expressed as mean \pm standard deviation and range

${ }^{b} n=10$; two shoulders had no band-like adhesions with the latissimus dorsi 


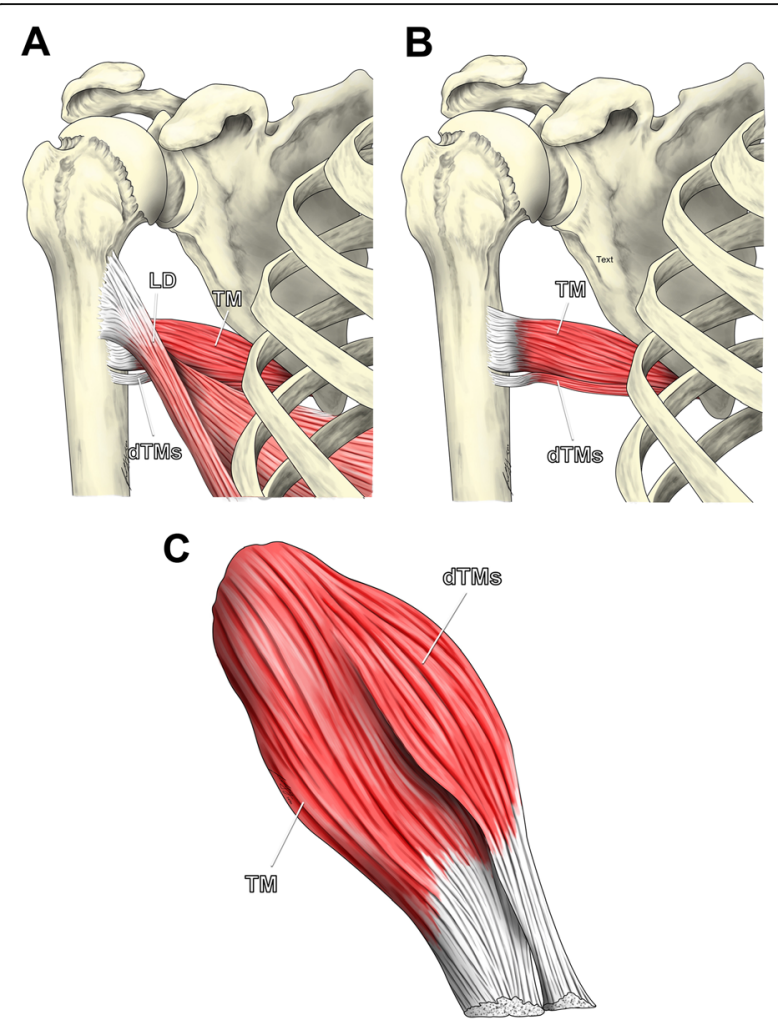

Fig. 2 a to $\mathbf{c}$ Schematic drawing of the latissimus dorsi (LD), teres major (TM) and distal teres major slip (dTMs) muscles and tendons. a: With the LD tendon attached, the dTMs insertion distally to the LD and TM tendons is visible. $\mathbf{b}$ : The drawing shows the separate but continuous insertion of the teres major and dTMs tendons after detachment of the LD tendon. $\mathbf{c}$ : Note the ventral location of the dTMs muscle belly relative to the TM muscle belly

Several surgical techniques have been described to transfer LD in cases of posteroinferior rotator cuff insufficiency, with or without TM $[2,5,26,27]$. More recently, an isolated LD transfer was favored in concomitant reverse total shoulder arthroplasty, particularly in cases of combined pseudoparalysis [28, 29] of active elevation and external rotation [30-32]. This might be even more beneficial in patients with subscapularis muscle insufficiency, to prevent further weakening of the internal rotation force of the shoulder with a transformation of two internal rotators into external rotators. The LD tendon transfer can be performed using a single $[5,26,30-34]$ or double incision technique [5, 26, 30-34]. In particular, for the single incision technique, the findings of the present study can contribute to improving the surgical safety by providing a deeper understanding of the surgical anatomy. We identified a separate muscle belly of the TM with a separated and more distal tendon insertion in three-quarters of the shoulder specimen examined. A specific band-like connection between the LD tendon and dTMs was found to be located approximately $5 \mathrm{~cm}$ proximal to the tendon insertion. A fascial-like connection between LD and dTMs has been described previously [14]. However, we could describe the distinct location of this important connection that needs to be released (together with the interconnections between LD and TM) in isolated LD tendon transfers in order to achieve appropriate tendon excursion and to minimize tension. Moreover, it remains controversial whether an isolated single-incision LD transfer should be performed underneath TM [31] or through a split within the muscle, as introduced by Popescu et al. [30]. The LD transfer passage within the TM muscle seems to be feasible just between the TM and dTMs. Comparing the figures of that study to our findings, it remains possible that the transfer was actually performed in the study by Popescu et al. [30]. Yet, it remains necessary to study how well and to what extent the TM and dTMs can be separated from each other without jeopardizing them.

In patients with irreparable subscapularis tears, pectoralis major transfer [35-37] has been the most commonly performed procedure for glenohumeral joint preservation with good to excellent long-term results [38]. More recently, ventral LD transfer has been described as an alternative technique for irreparable subscapularis tears [7, 9]. As in the single-incision LD transfer for posterosuperior tears, locating and harvesting the tendon in a ventral LD transfer are performed similarly. The findings of this anatomic study could help to improve the safety and efficiency of ventral LD transfers in patients with irreparable subscapularis insufficiency.

A limitation is that we could not study the function as well as neurovascular supply pattern of the dTMs, as it was not feasible in our cadaveric shoulder specimen. The lack of tone and neuromuscular control and the alteration of elasticity due to the freeze-thaw process should also be noticed when interpreting our results. The macroscopic appearance and excursion are suggestive of an additional distal teres major muscle slip. However, in order to confirm the dTMs, further anatomical studies (of function, innervation patterns, histology, and pennation angles) are necessary. Further, we did not evaluate whether the dTMs was present unilaterally or bilaterally, as only one shoulder specimen of each donor was available. We also did not study the presence of the dTMs in different ethnic groups than white American. Therefore, the presence of the dTMs may be the result of ethnical specificity and needs to be further investigated. The authors believe that this new anatomic knowledge is of importance in the field of tendon transfers around the shoulder.

\section{Conclusions}

This is the first macroscopic description of an additional distal slip of the teres major muscle. The dTMs has a separate (distal) but continuous (mediolateral) insertion at the humerus within a common epimyseal sheet 
around the TM. The dTMs tendon is visible during the deltopectoral approach and can therefore provide a lead structure, particularly in ventral LD transfers with the deltopectoral approach.

\section{Abbreviations}

TM: Teres major; dTMs: Distal teres major slip; LD: Latissimus dorsi

\section{Acknowledgements}

The authors wish to thank Mr. Andreas Bauer (Gottfried Schatz Research Center for Cell Signaling, Metabolism and Aging; Macroscopic and Clinical Anatomy; Medical University of Graz, Austria) for the drawings and illustrations. We would like to thank Editage (www.editage.com) for English language editing.

\section{Authors' contributions}

LE: Project development, data collection, data analysis, manuscript writing. MJ: Data analysis, manuscript editing. MR: Data collection, data analysis. MD: Manuscript editing. SB: Manuscript editing. KW: Manuscript editing. PB: Project development, data collection, manuscript writing. All authors have read and approved the manuscript.

\section{Funding}

There was no outside funding or grants received that assisted in this study.

\section{Availability of data and materials}

Not applicable.

\section{Declarations}

Ethics approval and consent to participate

The cantonal ethics committee Zurich, Switzerland obtained approval for this study (project number, 2018-00588).

\section{Consent for publication}

Not applicable.

\section{Competing interests}

All authors, their immediate family, and any research foundation with which they are affiliated did not receive any financial payments or other benefits from any commercial entity related to the subject of this article.

\section{Author details}

${ }^{1}$ Department of Orthopedics, Balgrist University Hospital, University of Zurich, Forchstrasse 340, 8008 Zurich, Switzerland. ${ }^{2}$ Gottfried Schatz Research Center for Cell Signaling, Metabolism and Aging, Macroscopic and Clinical Anatomy, Medical University of Graz, Graz, Austria.

Received: 30 October 2020 Accepted: 7 April 2021

Published online: 16 April 2021

\section{References}

1. L'Episcopo JB. Tendon transplantation in obstetrical paralysis. Am J Surg. 1936;25:122-5

2. Gerber C, Vinh TS, Hertel R, Hess CW. Latissimus dorsi transfer for the treatment of massive tears of the rotator cuff. A preliminary report. Clin Orthop Relat Res. 1988;232:51-61.

3. Gerber C, Maquieira G, Espinosa N. Latissimus dorsi transfer for the treatment of irreparable rotator cuff tears. J Bone Joint Surg Am. 2006;88(1): $113-20$.

4. Gerber C, Rahm SA, Catanzaro S, Farshad M, Moor BK. Latissimus dorsi tendon transfer for treatment of irreparable posterosuperior rotator cuff tears: long-term results at a minimum follow-up of ten years. J Bone Joint Surg Am. 2013;95(21):1920-6.

5. Boileau P, Chuinard C, Roussanne Y, Neyton L, Trojani C. Modified latissimus dorsi and teres major transfer through a single delto-pectoral approach for external rotation deficit of the shoulder: as an isolated procedure or with a reverse arthroplasty. J Shoulder Elb Surg. 2007;16(6):671-82.
6. Henseler JF, Nagels J, van der Zwaal P, Nelissen RG. Teres major tendon transfer for patients with massive irreparable posterosuperior rotator cuff tears: short-term clinical results. Bone Joint J. 2013;95-B(4):523-9.

7. Elhassan B, Christensen TJ, Wagner ER. Feasibility of latissimus and teres major transfer to reconstruct irreparable subscapularis tendon tear: an anatomic study. J Shoulder Elb Surg. 2014;23(4):492-9.

8. Kany J, Guinand R, Croutzet P, Valenti P, Werthel JD, Grimberg J. Arthroscopic-assisted latissimus dorsi transfer for subscapularis deficiency. Eur J Orthop Surg Traumatol. 2016;26(3):329-34.

9. Mun SW, Kim JY, Yi SH, Baek CH. Latissimus dorsi transfer for irreparable subscapularis tendon tears. J Shoulder Elb Surg. 2018;27(6):1057-64.

10. Wang AA, Strauch RJ, Flatow EL, Bigliani LU, Rosenwasser MP. The teres major muscle: an anatomic study of its use as a tendon transfer. J Shoulder Elb Surg. 1999;8(4):334-8.

11. Pearle AD, Kelly BT, Voos JE, Chehab EL, Warren RF. Surgical technique and anatomic study of latissimus dorsi and teres major transfers. J Bone Joint Surg Am. 2006;88(7):1524-31.

12. Beck PA, Hoffer MM. Latissimus dorsi and teres major tendons: separate or conjoint tendons? J Pediatr Orthop. 1989;9(3):308-9.

13. Morelli M, Nagamori J, Gilbart M, Miniaci A. Latissimus dorsi tendon transfer for massive irreparable cuff tears: an anatomic study. J Shoulder Elb Surg. 2008;17(1):139-43.

14. Goldberg BA, Elhassan B, Marciniak S, Dunn JH. Surgical anatomy of latissimus dorsi muscle in transfers about the shoulder. Am J Orthop (Belle Mead NJ). 2009;38(3):E64-7.

15. lamsaard S, Thunyaharn N, Chaisiwamongkol K, Boonruangsri P, Uabundit N, Hipkaeo W. Variant insertion of the teres major muscle. Anat Cell Biol. 2012; 45(3):211-3.

16. Dancker M, Lambert S, Brenner E. Teres major muscle - insertion footprint. J Anat. 2017;230(5):631-8

17. Beger O, Koc T, Beger B, Kayan G, Uzmansel D, Olgunus ZK. Quantitative assessment of the growth dynamics of the teres major in human fetuses. Surg Radiol Anat. 2018;40(12):1349-56.

18. Ranade AV, Rai R, Rai AR, Dass PM, Pai MM, Vadgaonkar R. Variants of latissimus dorsi with a perspective on tendon transfer surgery: an anatomic study. J Shoulder Elb Surg. 2018;27(1):167-71.

19. Macalister A. Additional observations on the muscular anomalies in human anatomy. (third series) with a catalogue of the principal muscular variations hitherto Publisher, vol. 25. Dublin: Academy; 1875.

20. Le Double AF. Traité des Variations du Systéme Musculaire de l'homme et de leur Signification au Point de Vue de l'Anthropologie Zoologique. 2nd ed. Paris: Libraire C. Reinwald, Schleicher Freres; 1897.

21. Quandros LS, Babu A, Bhat N, Ankolekar VH, D'Souza AS. Variant musculotendinous slip between teres major and triceps brachii. Online J Health Allied Sci. 2013;12:3

22. Blandin FP. Nouveaux Eléments d'Anatomié Descriptive, vol. 1. Paris: J.B. Bailliere; 1838

23. Aggarwal A, Kaur H, Sahni D, Aggarwal A. Four-headed biceps brachii muscle with variant course of musculocutaneous nerve: anatomical and clinical insight. Int J Anat Var. 2009;2:127-30.

24. Mori M. Statistics on the musculature of the Japanese. Okajimas Folia Anat Jpn. 1964;40:195-300.

25. Moatshe G, Marchetti DC, Chahla J, Ferrari MB, Sanchez G, Lebus GF, et al. Qualitative and quantitative anatomy of the proximal Humerus muscle attachments and the axillary nerve: a cadaveric study. Arthroscopy. 2018; 34(3):795-803.

26. Shi LL, Cahill KE, Ek ET, Tompson JD, Higgins LD, Warner JJ. Latissimus Dorsi and Teres major transfer with reverse shoulder arthroplasty restores active motion and reduces pain for Posterosuperior cuff dysfunction. Clin Orthop Relat Res. 2015;473(10):3212-7.

27. Wieser K, Ernstbrunner L, Zumstein MA. Surgical Management of Massive Irreparable Cuff Tears: latissimus Dorsi transfer for Posterosuperior tears. Curr Rev Musculoskelet Med. 2020;13(5):605.

28. Ernstbrunner L, El Nashar R, Bouaicha S, Wieser K, Gerber C. Scapular morphologic characteristics and rotator cuff tear pattern are independently associated with chronic Pseudoparalyis: a matched-pair analysis of patients with massive rotator cuff tears. Am J Sports Med. 2020;48(9):2137.

29. Ernstbrunner L, El Nashar R, Favre P, Bouaicha S, Wieser K, Gerber C. Chronic Pseudoparalysis needs to be distinguished from Pseudoparesis: a structural and biomechanical analysis. Am J Sports Med. 2021;49(2):291-7. 
30. Popescu IA, Bihel T, Henderson D, Martin Becerra J, Agneskirchner J, Lafosse L. Functional improvements in active elevation, external rotation, and internal rotation after reverse total shoulder arthroplasty with isolated latissimus dorsi transfer: surgical technique and midterm follow-up. J Shoulder Elb Surg. 2019;28(12):2356-63.

31. Ortmaier R, Resch H, Hitzl W, Mayer M, Blocher M, Vasvary I, et al. Reverse shoulder arthroplasty combined with latissimus dorsi transfer using the bone-chip technique. Int Orthop. 2014;38(3):553-9.

32. Puskas GJ, Catanzaro S, Gerber C. Clinical outcome of reverse total shoulder arthroplasty combined with latissimus dorsi transfer for the treatment of chronic combined pseudoparesis of elevation and external rotation of the shoulder. J Shoulder Elb Surg. 2014;23(1):49-57.

33. Boileau P, Rumian AP, Zumstein MA. Reversed shoulder arthroplasty with modified L'Episcopo for combined loss of active elevation and external rotation. J Shoulder Elb Surg. 2010;19(2 Suppl):20-30.

34. Gerber C, Pennington SD, Lingenfelter EJ, Sukthankar A. Reverse Delta-III total shoulder replacement combined with latissimus dorsi transfer. A preliminary report. J Bone Joint Surg Am. 2007;89(5):940-7.

35. Jost B, Puskas GJ, Lustenberger A, Gerber C. Outcome of pectoralis major transfer for the treatment of irreparable subscapularis tears. J Bone Joint Surg Am. 2003;85-A(10):1944-51.

36. Resch H, Povacz P, Ritter E, Matschi W. Transfer of the pectoralis major muscle for the treatment of irreparable rupture of the subscapularis tendon. J Bone Joint Surg Am. 2000;82(3):372-82.

37. Wirth MA, Rockwood CA Jr. Operative treatment of irreparable rupture of the subscapularis. J Bone Joint Surg Am. 1997:79(5):722-31.

38. Ernstbrunner L, Wieser K, Catanzaro S, Agten CA, Fornaciari P, Bauer DE, et al. Long-term outcomes of pectoralis major transfer for the treatment of irreparable subscapularis tears: results after a mean follow-up of 20 years. J Bone Joint Surg Am. 2019;101(23):2091-100

\section{Publisher's Note}

Springer Nature remains neutral with regard to jurisdictional claims in published maps and institutional affiliations.

Ready to submit your research? Choose BMC and benefit from:

- fast, convenient online submission

- thorough peer review by experienced researchers in your field

- rapid publication on acceptance

- support for research data, including large and complex data types

- gold Open Access which fosters wider collaboration and increased citations

- maximum visibility for your research: over $100 \mathrm{M}$ website views per year

At $\mathrm{BMC}$, research is always in progress.

Learn more biomedcentral.com/submissions 